\title{
Unifocality as Prognostic Factor for Unilateral Retinoblastoma: Preliminary Results of 32 Eyes Treated with Intra-Arterial Chemotherapy Alone
}

\author{
Sonia De Francesco ${ }^{1 *}$, Alessandro Di Maggioㄹ, Paolo Galluzzi², Sara Leonini², Sandra Bracco², \\ Cristina Menicacci ${ }^{1}$, Matteo Barchitta ${ }^{1}$, Giulio Bagnacci ${ }^{3}$ and Theodora Hadjistilianou ${ }^{1}$ \\ ${ }^{1}$ Ophthalmology Department and Retinoblastoma Referral Center, University of Siena, Policlinico 'Santa Maria alle Scotte, \\ Siena, Italy \\ ${ }^{2}$ Unit of Neuroimaging and Neurointervention, Azienda Ospedaliera Universitaria Senese, Siena, Italy \\ ${ }^{3}$ Department of Radiological Sciences, Unit of Diagnostic Imaging, Azienda Ospedaliera Universitaria Senese, Siena, Italy
}

*Corresponding author: Sonia De Francesco, Ophthalmology Department and Retinoblastoma Referral Center, University of Siena,

Policlinico 'Santa Maria alle Scotte, Siena, Italy

\section{ARTICLE INFO}

Received: 幽 August 31, 2021

Published: 幽 September 09, 2021

Citation: Sonia De Francesco, Alessandro Di Maggio, Paolo Galluzzi, Sara Leonini, Sandra Bracco, et al., Unifocality as Prognostic Factor for Unilateral Retinoblastoma: Preliminary Results of 32 Eyes Treated with Intra-Arterial Chemotherapy Alone. Biomed J Sci \& Tech Res 38(4)-2021. BJSTR. MS.ID.006191.

Abbreviations: RB: Retinoblastoma; IAC: Intra Arterial Chemotherapy; IVC: Intravenous Chemotherapy; MRI: Magnetic Resonance Imaging; ADC: Apparent Diffusion Coefficient

\section{ABSTRACT}

Purpose: To evaluate the role of intra-arterial chemotherapy (IAC) in the management of unilateral, unifocal retinoblastoma (RB) as a single therapy, associated to neither focal nor systemic adjunctive therapies.

Methods: Prospective, single center, interventional case series of 32 consecutive eyes diagnosed with unilateral unifocal RB and treated exclusively with selective ophthalmic intra-arterial chemotherapy, with no adjunctive systemic or focal treatments.

Results: Full regression of the lesion was observed in 30 eyes (93.75\%). 2 eyes were enucleated. Ophthalmoscopic remissions type I and III with higher calcific component were achieved. Additionally, neither recurrences nor new tumors appeared during the patient follow-up, which ranged from 10 months to 13 years.

Conclusion: Selective intra-arterial chemotherapy has demonstrated to be highly effective in terms of disease control and anatomical preservation in case of unilateral unifocal disease, without requiring any additional systemic and/or focal therapy.

Keywords: Retinoblastoma; Intra-Arterial Chemotherapy; Oncology; Unilateral Retinoblastoma

\section{Introduction}

Retinoblastoma (RB) is the most common intraocular malignancy of in childhood. Approximately $60 \%$ of cases are unilateral while $40 \%$ are bilateral. With respect to gender distribution, there is male predominance 1.2:1 with survival rate ranging from $86-92 \%$. It is generally diagnosed in patients at an average age of 18 months, with $90 \%$ cases diagnosed younger than 5 years of age [1,2]. With recent advances in research and clinical trials, there has been a paradigm shift in the treatment protocols of
RB. Enucleation is required for extensive RB. Initial treatment can be conservative when preservation of residual visual function, even minimal, appears to be possible. It usually comprises neoadjuvant Intravenous Chemotherapy (IVC) followed by local treatments of each tumor (Laser, Thermotherapy, Cryotherapy, Plaque radiotherapy) [3]. These treatments allow good eye preservation rates and decrease the indications for external beam radiation (possible cause of second tumors in the irradiation area and beyond) but are not free of ocular and systemic toxicity. In order to improve 
the efficacy of intraocular penetration of the chemotherapeutic agents and therefore local tumor control, it has been proposed to administer chemotherapy via the intra-arterial route directly into the ophthalmic artery [4,5]. Melphalan, topotecan and carboplatin are the chemotherapeutic agents currently used in the treatment of RB.

\section{Methods}

This is a single center, prospective, interventional case series conducted at the Referral Center for Retinoblastoma of University of Siena, with the collaboration of Unit of Neuroimaging and Neuro intervention from May 2008 to April 2021. The study was approved by the Institutional Review Board following the tenets of the Declaration of Helsinki. Since all the patients were minor, written consent for publication has been obtained from all patients' parents. Thirty two eyes of 32 consecutive patients, $18(60 \%)$ males and $14(40 \%)$ females, mean age at diagnosis $21.83 \pm 16.44$ months, with unilateral unifocal RB who underwent IAC alone were included in the study. The unifocality of the lesion represented a main inclusion criterion and it was assessed either by MRI and ultrasounds performed at diagnosis or by ocular fundus examination at diagnosis in case of stage $A$ and $B$ tumors and after tumor regression for advanced stage disease. Informed consent was obtained from all the participants and a proforma was designed to collect the data of patients including name, age at the diagnosis, gender, laterality, stage of disease and any history of previous treatments. All the patients underwent genetic testing at diagnosis. Examination under anaesthesia was performed with photographic documentation of clinical findings using Ret Cam II (Clarity medical system, Pleasanton, CA, USA), Ultrasound Examination of Anterior (UBM) and posterior segments was performed too. Magnetic Resonance Imaging (MRI) was performed in all the patients on a 1.5-T MR system (Siemens Avanto, Erlagen, Germany), according to the protocol of European Retinoblastoma Imaging Collaboration [6].

We added DWI-sequences (b values: 0 and $1000 \mathrm{~s} / \mathrm{mm} 2$, FOV 230, thickness 2.6 mm, TR 3200 ms, TE 100 ms, matrix 192 x 192, diffusion directions 3). Apparent Diffusion Coefficient (ADC)-values were extrapolated using a hand-drafted Region-of-Interest (ROI) ; 1 to 5 ADC-values (depending on the tumor size) were obtained.
State of anticoagulation was achieved by intravenous heparin (75 $\mathrm{IU} / \mathrm{kg}$ ) as described in other studies. Femoral artery region was selected to place a 4-French arterial sheath. Under fluoroscopic guidance, the 4 French (1.3-mm diameter) catheter was guided into the ipsilateral internal carotid artery. Chemotherapeutic agents (Melphalan alone or in association) were infused at the pre-established doses in a pulsatile fashion over 30 minutes. After infusion, a confirmatory angiogram was taken again to look for vasospasm. After the completion of the procedure, catheters were removed, femoral sheath was withdrawn and manual compression of femoral artery was done to achieve haemostasis. After 6 hours clinical observation, child was discharged on the day after. IAC was repeated at 4 weeks intervals. During treatment, patients were followed-up at 4 weeks interval. Treatment outcomes were shown in terms of tumor ophthalmoscopic remission, preservation of anatomy of the globe and complications of the procedure. MRI was performed at diagnosis, during treatment (in stage E patients), three months after the last infusion, and annually to evaluate eyeball growth.

\section{Results}

A total of 32 eyes from 32 patients were examined and treated. All 32 eyes were treatment-naïve. No family history was referred. 6 cases out of 32 (18.75\%) were de novo mutations. ABC classification of RB was used to assess the stage of the disease. Among thirty two eyes, 11 (31.25\%) were diagnosed stage B, 4 (12.5\%) were stage C, $8(25 \%)$ stage D and $9(28.12 \%)$ were stage E. Most of the lesions were localized at the posterior pole, while the others were localized in peripheral retina and only 1 (3\%) was iuxtapapillary. Vitreous seeding, subretinal seeding and both vitreous plus subretinal seeding were present in respectively 5 (15.62\%), $3(9.37 \%)$ and $2(6.25 \%)$ patients (Table 1). Mean ADC (Apparent Diffusion Coefficient) at diagnosis was $744 \pm 225.95$ (range 432-1451). 9 (28.12\%) patients underwent IAC with Melphalan alone. 16 (50\%) patients received the association of Melphalan and Topotecan. 7 (21.87\%) patients received the association of Melphalan, Topotecan and Carboplatin. Associations and dosage of chemotherapeutic agents were decided according to clinical stage, in collaboration with the pediatric oncologist within the GOM (Multidisciplinary Oncology Group) where the cases were discussed and analyzed (Table 1).

Table 1: Summary of Patients' characteristics, therapeutic protocol and globe response to Intra-Arterial Chemotherapy.

\begin{tabular}{|c|c|c|c|c|c|c|c|c|c|c|c|c|}
\hline Patient & Sex & $\begin{array}{c}\text { Age at } \\
\text { diagnosis } \\
\text { and } \\
\text { treatment }\end{array}$ & $\begin{array}{c}\text { Stage at } \\
\text { diagnosis } \\
\text { ABC } \\
\text { (TNM8) }\end{array}$ & Seeding & Mutation & $\begin{array}{l}\text { Chemo- } \\
\text { therapeu- } \\
\text { tic agents }\end{array}$ & $\begin{array}{c}\text { Doses } \\
\text { (mg) }\end{array}$ & $\begin{array}{c}\mathrm{N}^{\circ} \text { of } \\
\text { infusions }\end{array}$ & $\begin{array}{l}\text { Transient } \\
\text { complica- } \\
\text { tions }\end{array}$ & $\begin{array}{c}\text { Perma- } \\
\text { nent com- } \\
\text { plications }\end{array}$ & $\begin{array}{c}\text { Remission } \\
\text { pattern }\end{array}$ & F-Up \\
\hline 1 & F & $3 y 7 m$ & $\begin{array}{c}\text { C(cT1B, } \\
\text { cN0, cM0, } \\
\text { H0) }\end{array}$ & NS & Negative & Melph & 5 & 3 & $\begin{array}{l}\text { Eyelid and } \\
\text { frontal rash }\end{array}$ & - & I & $13 y$ \\
\hline 2 & M & $3 y 8 m$ & $\begin{array}{c}\text { B(cT1A, } \\
\text { cN0, cM0, } \\
\text { H0) }\end{array}$ & NS & Negative & Melph & 5 & 3 & - & CA & I & $11 y$ \\
\hline
\end{tabular}




\begin{tabular}{|c|c|c|c|c|c|c|c|c|c|c|c|c|}
\hline 3 & M & $2 \mathrm{y} 1 \mathrm{~m}$ & $\begin{array}{c}\text { B(cT1A, } \\
\text { cN0, cM0, } \\
\text { H0) }\end{array}$ & NS & Negative & Melph & 5 & 3 & $\begin{array}{l}\text { Eyelid edema } \\
\text { and rash }\end{array}$ & $\begin{array}{l}\text { Sectorial } \\
\text { CA }\end{array}$ & III & $10 \mathrm{y}$ \\
\hline 4 & $\mathrm{~F}$ & $8 m$ & $\begin{array}{c}\text { C(cT1B, } \\
\text { cN0, cM0, } \\
\text { H0) }\end{array}$ & NS & Negative & Melph & 4 & 3 & $\begin{array}{c}\text { Macular } \\
\text { hemorrhage }\end{array}$ & $\begin{array}{l}\text { Bulbar sub- } \\
\text { atrophy }\end{array}$ & IV & $10 y$ \\
\hline 5 & M & $1 \mathrm{y} 1 \mathrm{~m}$ & $\begin{array}{c}\text { B(cT1A, } \\
\text { cN0, cM0, } \\
\text { H0) }\end{array}$ & NS & Negative & Melph & 4 & 3 & $\begin{array}{l}\text { Eyelid and } \\
\text { frontal rash }\end{array}$ & $\begin{array}{c}\text { Bulbar sub- } \\
\text { atrophy/ } \\
\text { CA }\end{array}$ & I & $10 y$ \\
\hline 6 & $\mathrm{~F}$ & $8 \mathrm{~m}$ & $\begin{array}{c}\text { B(cT1A, } \\
\text { cN0, cM0, } \\
\text { H0) }\end{array}$ & NS & Negative & Melph & 4 & 3 & - & - & I & $10 y$ \\
\hline 7 & $\mathrm{~F}$ & 1 y $3 \mathrm{~m}$ & $\begin{array}{c}\text { E(cT3D, } \\
\text { cN0, cM0, } \\
\text { H0) }\end{array}$ & NS & Negative & Melph & 4 & 4 & Eyelid edema & $\begin{array}{l}\text { Bulbar sub- } \\
\text { atrophy/ } \\
\text { CA }\end{array}$ & I & $8 y$ \\
\hline 8 & M & $1 \mathrm{y} 10 \mathrm{~m}$ & $\begin{array}{c}\text { D(cT2B, } \\
\text { cN0, cM0, } \\
\text { H0) }\end{array}$ & NS & Negative & $\begin{array}{l}\text { Melph+ } \\
\text { Topo }\end{array}$ & $4+0.3$ & 6 & - & - & III & $7 y$ \\
\hline 9 & M & $1 \mathrm{y} 2 \mathrm{~m}$ & $\begin{array}{c}\text { B(cT1A, } \\
\text { cN0, cM0, } \\
\text { H0) }\end{array}$ & DS & $\begin{array}{c}\text { Met- } \\
\text { 484Valfs*7 } \\
\text { mosaic }\end{array}$ & $\begin{array}{l}\text { Melph+ } \\
\text { Topo }\end{array}$ & $4+0.3$ & 6 & - & - & III & $7 y$ \\
\hline 10 & $\mathrm{~F}$ & 1y $10 \mathrm{~m}$ & $\begin{array}{c}\text { D(cT2B, } \\
\text { cN0, cM0, } \\
\text { H0) }\end{array}$ & NS & Negative & Melph & 4 & 6 & - & - & I & $5 y$ \\
\hline 11 & $\mathrm{~F}$ & $1 \mathrm{y} 4 \mathrm{~m}$ & $\begin{array}{c}\text { D(cT2B, } \\
\text { cN0, cM0, } \\
\text { H0) }\end{array}$ & SRS & Negative & $\begin{array}{l}\text { Melph+ } \\
\text { Topo }\end{array}$ & $4+0.3$ & 4 & - & $\mathrm{CA}$ & III & $5 y$ \\
\hline 12 & $\mathrm{~F}$ & $1 \mathrm{y} 7 \mathrm{~m}$ & $\begin{array}{c}\mathrm{B}(\mathrm{cT} 1 \mathrm{~A}, \\
\mathrm{cN} 0, \mathrm{cM} 0 \\
\mathrm{H} 0)\end{array}$ & NS & $\begin{array}{l}\text { P.T307I } \\
\text { mutata }\end{array}$ & $\begin{array}{l}\text { Melph+ } \\
\text { Topo }\end{array}$ & $4+0.3$ & 4 & - & - & III & $5 y$ \\
\hline 13 & M & $1 y$ & $\begin{array}{c}\text { B(cT1A, } \\
\text { cN0, cM0, } \\
\text { H0) }\end{array}$ & NS & Negative & Melph & 4 & 4 & - & - & III & $4 y$ \\
\hline 14 & M & $3 y 4 m$ & $\begin{array}{c}\mathrm{D}(\mathrm{cT} 2 \mathrm{~B} \\
\mathrm{cN} 0, \mathrm{cM} 0 \\
\mathrm{H} 0)\end{array}$ & SRS & Negative & $\begin{array}{l}\text { Melph+ } \\
\text { Topo }\end{array}$ & $4+0.3$ & 6 & $\begin{array}{l}\text { Eyelid edema } \\
\text { and rash }\end{array}$ & $\mathrm{CA}$ & I & $4 y$ \\
\hline 15 & M & $7 \mathrm{y} 10 \mathrm{~m}$ & $\begin{array}{c}\text { D(cT2B, } \\
\text { cN0, cM0, } \\
\text { H0) }\end{array}$ & NS & Negative & $\begin{array}{l}\text { Melph+ } \\
\text { Topo }\end{array}$ & $5+0.4$ & 6 & - & - & I & $4 y$ \\
\hline 16 & M & $1 \mathrm{y} 7 \mathrm{~m}$ & $\begin{array}{c}\text { C(cT1B, } \\
\text { cN0, cM0, } \\
\text { H0) }\end{array}$ & SRS & $\begin{array}{l}\text { Promoter } \\
\text { methylation }\end{array}$ & $\begin{array}{c}\text { Melph+ } \\
\text { Topo }\end{array}$ & $4+1$ & 3 & - & $\mathrm{CA}$ & I & $4 y$ \\
\hline 17 & $\mathrm{~F}$ & $1 \mathrm{y} 3 \mathrm{~m}$ & $\begin{array}{c}\text { E(cT3D, } \\
\text { cN0, cM0, } \\
\text { H0) }\end{array}$ & NS & $1875+72 \mathrm{~T}>\mathrm{C}$ & $\begin{array}{l}\text { Melph+ } \\
\text { Topo }\end{array}$ & $5+1$ & 4 & $\begin{array}{l}\text { Hemorrhagic } \\
\text { soffusion }\end{array}$ & $\begin{array}{l}\text { Hypotonia/ } \\
\text { bulbar } \\
\text { subatrophy }\end{array}$ & I & $3 y$ \\
\hline 18 & $\mathrm{~F}$ & $7 \mathrm{~m}$ & $\begin{array}{c}\text { E(cT3C, } \\
\text { cN0, cM0, } \\
\text { H0) }\end{array}$ & DS & Negative & $\begin{array}{c}\text { Melph+ } \\
\text { Topo+ Cp }\end{array}$ & $\begin{array}{c}3+0.3+ \\
30\end{array}$ & 6 & Cataract & Emyptosis & I & $3 y$ \\
\hline 19 & $\mathrm{~F}$ & $2 y 8 m$ & $\begin{array}{c}\text { E(cT3C, } \\
\text { cN0, cM0, } \\
\text { H0) }\end{array}$ & DS+SRS & Negative & $\begin{array}{l}\text { Melph+ } \\
\text { Topo }\end{array}$ & $4+1$ & 6 & $\begin{array}{l}\text { Late Vitreous } \\
\text { hemorrhage }\end{array}$ & - & I & $3 y$ \\
\hline 20 & $\mathrm{~F}$ & $9 \mathrm{~m}$ & $\begin{array}{c}\text { B(cT1A, } \\
\text { cN0, cM0, } \\
\text { H0) }\end{array}$ & NS & $\begin{array}{l}\text { C.-222delA } \\
\text { incerta }\end{array}$ & $\begin{array}{l}\text { Melph+ } \\
\text { Topo+ Cp }\end{array}$ & $\begin{array}{c}5+0.4+ \\
30\end{array}$ & 4 & Frontal rash & $\begin{array}{l}\text { Sectorial } \\
\text { CA }\end{array}$ & III & $2 y$ \\
\hline 21 & M & $10 \mathrm{~m}$ & $\begin{array}{c}\text { E(cT3C, } \\
\text { cN0, cM0, } \\
\text { H0) }\end{array}$ & ES & $\begin{array}{l}\text { Pr255X } \\
\text { mosaic }\end{array}$ & $\begin{array}{c}\text { Melph+ } \\
\text { Topo+ Cp }\end{array}$ & $\begin{array}{c}3+1+ \\
30\end{array}$ & 6 & - & - & I & $2 y$ \\
\hline 22 & M & $1 \mathrm{y} 4 \mathrm{~m}$ & $\begin{array}{c}\text { B(cT1A, } \\
\text { cN0, cM0, } \\
\text { H0) }\end{array}$ & NS & Arg255* & $\begin{array}{l}\text { Melph+ } \\
\text { Topo }\end{array}$ & $3+0.3$ & 5 & Frontal rash & $\mathrm{CA}$ & III & $2 y$ \\
\hline
\end{tabular}




\begin{tabular}{|c|c|c|c|c|c|c|c|c|c|c|c|c|}
\hline 23 & M & $1 \mathrm{y} 8 \mathrm{~m}$ & $\begin{array}{c}\text { B(cT1A, } \\
\text { cN0, cM0, } \\
\text { H0) }\end{array}$ & NS & Negative & $\begin{array}{l}\text { Melph+ } \\
\text { Topo }\end{array}$ & $3+1$ & 4 & - & - & I & $2 y$ \\
\hline 24 & M & $1 \mathrm{y} 11 \mathrm{~m}$ & $\begin{array}{l}\text { E(cT3D, } \\
\text { cN0, cM0, } \\
\text { H0) }\end{array}$ & DS & Negative & $\begin{array}{l}\text { Melph+ } \\
\text { Topo+ Cp }\end{array}$ & $4+1$ & 6 & $\begin{array}{c}\text { Frontal rash/ } \\
\text { madarosis }\end{array}$ & - & III & $2 y$ \\
\hline 25 & M & $1 \mathrm{y}$ & $\begin{array}{c}\text { E(cT3D, } \\
\text { cN0, cM0, } \\
\text { H0) }\end{array}$ & NS & Negative & $\begin{array}{l}\text { Melph+ } \\
\text { Topo }\end{array}$ & $4+1$ & 4 & - & - & III & $2 y$ \\
\hline 26 & M & $11 \mathrm{~m}$ & $\begin{array}{c}\text { E(cT3D, } \\
\text { cN0, cM0, } \\
\text { H0) }\end{array}$ & NS & Negative & $\begin{array}{l}\text { Melph+ } \\
\text { Topo }\end{array}$ & $4+1$ & 2 & $\begin{array}{c}\text { Frontal and } \\
\text { eyelid rash/ } \\
\text { Skin necrosis }\end{array}$ & $\begin{array}{l}\text { CA/ Skin } \\
\text { dyscromia }\end{array}$ & I & $18 \mathrm{~m}$ \\
\hline 27 & $\mathrm{~F}$ & $1 \mathrm{y} 9 \mathrm{~m}$ & $\begin{array}{c}\text { D(cT2B, } \\
\text { cN0, cM0, } \\
\text { H0) }\end{array}$ & ES & Negative & $\begin{array}{l}\text { Melph+ } \\
\text { Topo }\end{array}$ & $4+1$ & 3 & $\begin{array}{l}\text { Frontal } \\
\text { edema and } \\
\text { rash }\end{array}$ & $\begin{array}{l}\text { Sectorial } \\
\text { CA }\end{array}$ & III & $12 \mathrm{~m}$ \\
\hline 28 & $\mathrm{~F}$ & $2 \mathrm{y} 2 \mathrm{~m}$ & $\begin{array}{c}\text { C(cT1B, } \\
\text { cN0, cM0, } \\
\text { H0) }\end{array}$ & NS & Negative & $\begin{array}{c}\text { Melph+ } \\
\text { Topo+ Cp }\end{array}$ & $5+1$ & 3 & - & - & III & $12 \mathrm{~m}$ \\
\hline 29 & M & $2 \mathrm{y} 7 \mathrm{~m}$ & $\begin{array}{c}\text { E(cT3B, } \\
\text { cN0, cM0, } \\
\text { H0) }\end{array}$ & NS & Negative & $\begin{array}{l}\text { Melph+ } \\
\text { Topo }\end{array}$ & $4+1$ & 3 & - & - & I & EN \\
\hline 30 & M & $2 y$ & $\begin{array}{c}\text { D(cT2B, } \\
\text { cN0, cM0, } \\
\text { H0) }\end{array}$ & NS & Negative & $\begin{array}{l}\text { Melph+ } \\
\text { Topo }\end{array}$ & $4+1$ & 4 & $\begin{array}{l}\text { Eyelid and } \\
\text { frontal } \\
\text { oedema } \\
\text { and rash/ } \\
\text { Hemorragic } \\
\text { soffusion }\end{array}$ & - & III & $10 \mathrm{~m}$ \\
\hline 31 & M & $1 \mathrm{y} 4 \mathrm{~m}$ & $\begin{array}{c}\text { D(cT2B, } \\
\text { cN0, cM0, } \\
\text { H0) }\end{array}$ & NS & Negative & $\begin{array}{c}\text { Melph+ } \\
\text { Topo+ Cp }\end{array}$ & $4+1+30$ & 4 & - & - & & EN \\
\hline 32 & $\mathrm{~F}$ & $1 y$ & $\begin{array}{c}\text { B(cT1A, } \\
\text { cN0, cM0, } \\
\text { H0) }\end{array}$ & NS & Negative & $\begin{array}{c}\text { Meplh+ } \\
\text { Topo }\end{array}$ & $4+1$ & 5 & $\begin{array}{c}\text { Vitreous } \\
\text { hemorrage }\end{array}$ & - & & $10 \mathrm{~m}$ \\
\hline
\end{tabular}

Note: NS, no seeding; DS, diffuse vitreous seeding; ES, epitumoral seeding; SRS, sub-retinal seeding; Melph, melphalan; Topo, topotecan; Cp, carboplatinum; CA, chorioretinal atrophy.

Most of the patients received 3 or more infusions (mean number 4.2 , range 2 to 6). Full regression of the lesion was observed in 30 eyes (93.75\%). Complete regression was seen in 30 eyes (93.75\%). $2(6.25 \%)$ eyes were enucleated. Two regression patterns were noticed, I and III (with a higher calcific component). 15 (46.87\%) eyes reached ophthalmoscopic remission type I and 15 (46.87\%) type III (Figure 1). Transient complications included eyelid and frontal rush (2-6.25\%), eyelid edema and rush (3-9.37\%), macular hemorrhage ( $1-3.12 \%)$, hemorrhagic soffusion $(1-3.12 \%)$, late ischemic vitreous hemorrhage $(1-3.12 \%)$, isolated eyelid edema $(1-3.12 \%)$, frontal rush $(2-6.25 \%)$, frontal rush and madarosis (1
- 3.12\%), frontal and eyelid rush/skin necrosis (1 - 3.12\%), eyelid and frontal edema and rush/hemorragic soffusion (1 - 3.12\%). Permanent complications were chorioretinal atrophy (10 - 31.25\%) bulbar subatrophy ( $4-12.5 \%)$, emiptosis ( $2-6.25 \%)$, hypotonia (1 $-3.12 \%)$, cataract $(1-3.12 \%)$, skin dyschromia $(1-3.12 \%)$. Some patient had more than one permanent complication. 10 (31.25\%) patients had both transient and permanent complications. 12 out of $30(37.5 \%)$ had any transient and/or permanent complications (Figure 2). None of the patients showed ocular motility restriction, vascular accidents or systemic side effects. 


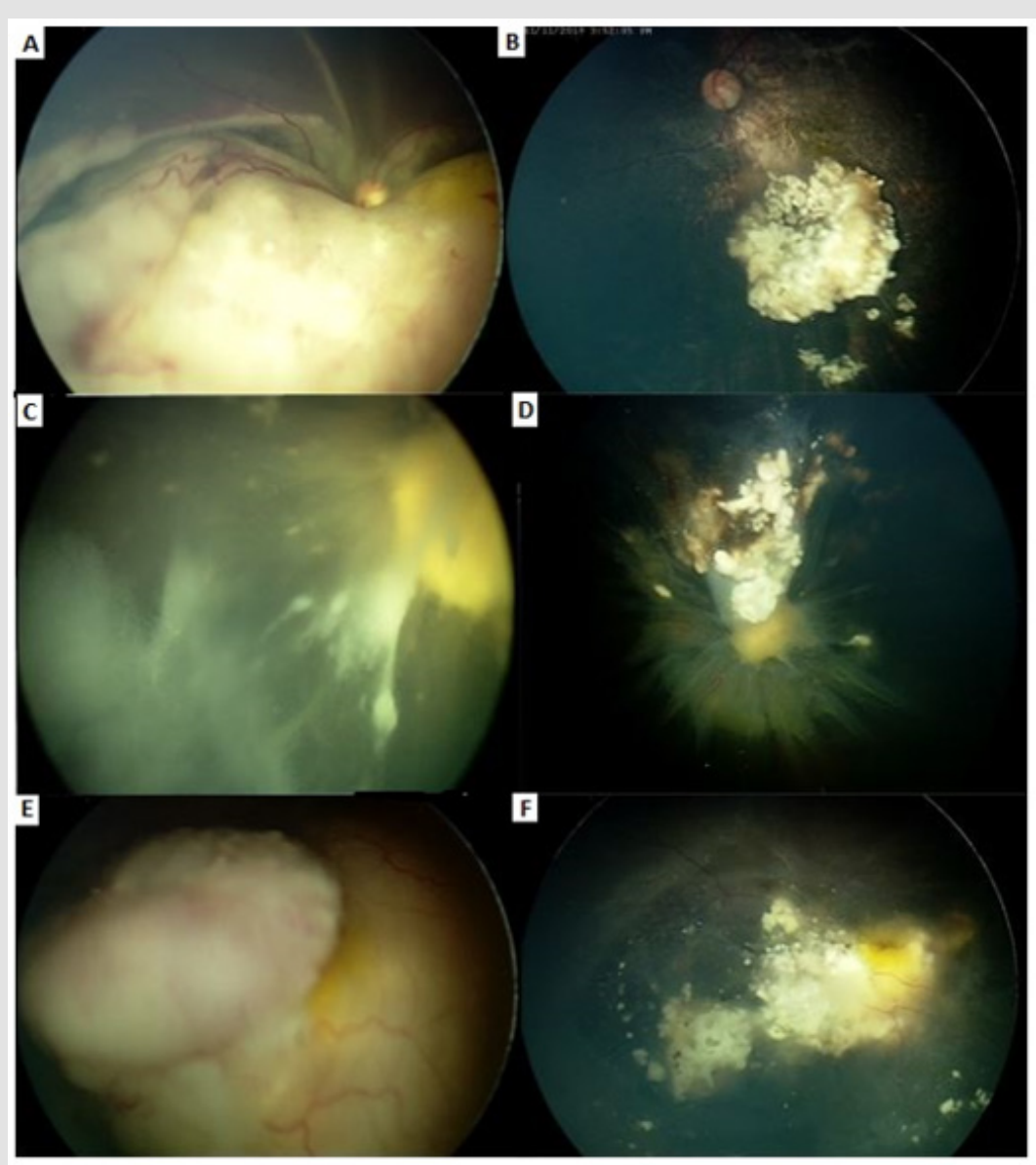

Figure 1:

A. A-B: 12 month old boy, stage E RB. 4 infusions, remission pattern type I.

B. C-D: 23 month old boy, stage E. 6 infusions, remission pattern type III.

C. E-F: 20 month old girl, stage D, 3 infusions, remission pattern type III.

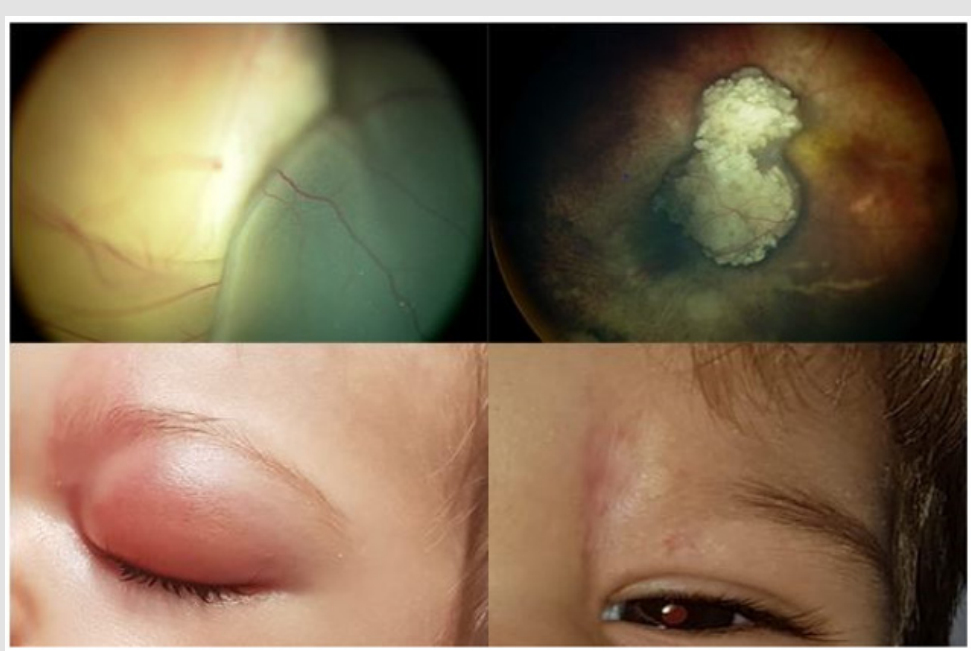

Figure 2:

A. 10 month old boy, stage $\mathrm{E}$

B. 2 infusions, remission pattern type I

C. Eyelid edema, frontal rush and

D. Permanent skin scar. 


\section{Discussion}

New therapeutic paradigms significantly improved the chances of anatomical and, often, functional preservation of the globe even with advanced stage diseases [7-9]. The introduction of selective Intra-Arterial Chemotherapy (IAC) represents a milestone in the treatment of RB because of its great effectiveness in terms of disease control with relatively low rates of systemic and local side effects. Abramson et al. reported a globe salvage rate up to $85.1 \%$ in treatment-naïve eyes according to Kaplan Meir estimate even in advanced disease (Stage D, E), although in this case series IAC was administered in association to focal treatments [10]. Our study confirms the great effectiveness of IAC, with an overall globe salvage rate of $93.75 \%$, even in patients with vitreous and/ or subretnal seeding, with no need of further focal therapies or intra-vitreous chemotherapy. In our case series, vitreous seeding, when present, completely regressed with IAC alone and we have not used intra-vitreal Melphalan in any of these patients. The good response of vitreous/subretinal seeding to IAC has been previously reported in literature. Abramson et al described a 2 -year probability of globe salvage of $83 \%$ in case of subretinal seeding alone, $64 \%$ for eyes with vitreous seeding only, and $80 \%$ for eyes with subretinal and vitreous seeding, with the majority of patients receiving 3 or less cycles of IAC with one to three drugs [11]. This globe retention rates may be partially explained by the fact that $61 \%$ of the eyes had previous treatments. The lower responsiveness to IAC of previously-treated RB has been described by several authors $[11,12]$ and may be explained by the selection of drug-resistant cell clones. The staging of tumor at baseline has a significant impact on treatment outcomes, although this relation is weaker than that of IVC, with excellent results for group B and C eyes, ranging from 95 to $100 \%$ of globe salvage in most of reported case series. Several studies described improved eye salvage rates in the IAC era, especially in advanced intraocular disease, supporting the superiority of IAC over IVC in group D eyes. Most of the patients of our series had stage B to D disease, only $28.12 \%$ of treated eyes were diagnosed as stage E. Although the incidence of systemic adverse effects has significantly reduced since the introduction of IAC, a certain number of local reactions have been described including lid oedema, orbital congestion, blephroptosis, ocular motility restriction, myelosupression, vasospasm, alopecia, nausea and vomiting [13-16]. In our study, only lid oedema, orbital congestion, vasospasm and skin hyperaemia occurred. No systemic toxicities were observed.

\section{Conclusion}

Choosing the proper therapeutic approach in patients with RB could be challenging, with multiple factors to be considered. If on one hand the main goal remains life salvage, we can't forget the importance of anatomical and/or functional preservation and the impact of this disease, and of course of the treatment procedures, on the quality of life of the little patient and his/her family. From our experience it comes to light a more favorable prognosis in case of unilateral unifocal RB which may be related to peculiar histological/genetic features, explaining the greater sensitivity to selective chemotherapy delivery. The hope for the future is to customize the treatment protocol basing on the combination of clinical, neuro-radiological and genetic/epigenetic parameters [17] in order to rise the efficacy of therapeutic procedures, reduce overtreatment and its impact on patient's and parent's quality of life $[18,19]$.

\section{Acknowledgment}

None to declare.

\section{Disclaimer}

None to declare.

\section{Conflict of Interest}

None to declare.

\section{Funding Sources}

None to declare.

\section{References}

1. Rodriguez Galindo C, Orbach DB, Vander Veen D (2015) Retinoblastoma. Pediatric Clinics of North America 62(1): 201-223.

2. Lohmann DR, Gallie BL, Adam MP, Ardinger HH, Pagon RA, et al. (2000) Retinoblastoma. SourceGeneReviews ${ }^{\circledR}$, Seattle (WA). In: Lohmann DR, Gallie BL, Adam MP, Ardinger HH, Pagon RA (Eds.)., University of Washington, Seattle, USA

3. Fabian ID, Onadim Z, Karaa E, Duncan C, Chowdhury T, et al. (2018) The management of retinoblastoma. Oncogene 37(12): 1551-1560.

4. Yamane 0T, Kaneko A, Mohri M (2004) The technique of ophthalmic arterial infusion therapy for patients with intraocular retinoblastoma. Int J Clin Oncol 9(2): 69-73.

5. Gobin YP, Dunkel IJ, Marr BP, Brodie SE, Abramson DH (2011) Intraarterial chemotherapy for the management of retinoblastoma: Fouryear experience. Arch Ophthalmol 129(6): 732-737.

6. De Graaf P, Göricke S, Rodjan F, Galluzzi P, Maeder P, et al. (2012) European Retinoblastoma Imaging Collaboration (ERIC). Guidelines for imaging retinoblastoma: imaging principles and MRI standardization. Pediatr Radiol 42(1): 2-14.

7. Hadjistilianou T, Coriolani G, Bracco S, Gennari P, Caini M, et al. (2014) Successful Treatment of Macular Retinoblastoma With Superselective Ophthalmic Artery Infusion of Melphalan. J Pediatr Ophthalmol Strabismus 51(1): 32-38

8. Shields CL, Manjandavida FP, Lally SE, Pieretti G, Arepalli SA, et al. (2014) Intra-arterial chemotherapy for retinoblastoma in 70 eyes: Outcomes based on the international classification of retinoblastoma. Ophthalmology 121(7): 1453-1460.

9. De Francesco S, Galluzzi P, Bracco S, Di Maggio A, Sgheri A (2020) Rescue intra-arterial chemotherapy in unilateral multirelapsed peripapillary retinoblastoma: Decision making and the role of MRI. Eur J Ophthalmol 9: 1120672120957586. 
10. Abramson DH, Daniels AB, Marr BP, Francis JH, Brodie SE, et al. (2016) Intra-arterial chemotherapy (ophthalmic ar tery chemosurger y) for group D retinoblastoma. PloS one 11(1): e0146582.

11. Abramson DH, Marr BP, Dunkel IJ, Brodie S, Zabor EC, et al. (2012) Intraarterial chemotherapy for retinoblastoma in eyes with vitreous and/or subretinal seeding: 2-year results. Br J Ophthalmol 96(4): 499-502.

12. Gobin YP, Dunkel IJ, Marr BP, Brodie SE, Abramson D (2011) Intraarterial chemotherapy for the management of retinoblastoma: four-year experience. Arch Ophthalmol 129(6): 732-737.

13. Vajzovic LM, Murray TG, Aziz Sultan MA, Schefler AC, Wolfe SQ et al. (2011) Supraselective intra-arterial chemotherapy: evaluation of treatment-related complications in advanced retinoblastoma. Clin Ophthalmol 5: 171-176.

14. Lee V, Hungerford JL, Bunce C, Ahmed F, Kingston JE, et al. (2003) Globe conserving treatment of the only eye in bilateral retinoblastoma. $\mathrm{Br} \mathrm{JO}$ phthalmol 87(11): 1374-1380.

\section{ISSN: 2574-1241}

DOI: 10.26717/BJSTR.2021.38.006191

Sonia De Francesco. Biomed J Sci \& Tech Res

(c) (P) This work is licensed under Creative

Submission Link: https://biomedres.us/submit-manuscript.php
15. Cui Y, Luo R, Wang R, Liu H, Zhang C, et al. (2018) Correlation between conventional MR imaging combined with diffusion-weighted imaging and histopathologic findings in eyes primarily enucleated for advanced retinoblastoma: a retrospective study. Eur Radiol 28(2): 620-629.

16. Galluzzi P (2018) Potential Value of Apparent Diffusion Coefficient (ADC) in First-Line Treatment of Retinoblastoma. EC Ophthalmology 9(3): 109-118.

17. Mc Evoya, Justina D, Michael A Dyer (2015) Genetic and Epigenetic Discoveries in Human Retinoblastoma. Crit Rev Oncog0 20(3-4): $217-$ 225.

18. Collins MLZ, Bregman J, Ford JS, Shields CL (2019) Depression, Anxiety, and Stress in Parents of Patients With Retinoblastoma. Am J Ophthalmol 207: 130-143.

19. Holt C (2020) Treatment for Naive Unilateral Unifocal Retinoblastoma Oncology Times 42(18): 1-9.

$\begin{array}{ll}\text { BIOMEDICAL } & \text { Assets of Publishing with us } \\ \text { RESEARCHES } & \text { - Global archiving of articles } \\ & \text { - Immediate, unrestricted online access } \\ & \text { - Rigorous Peer Review Process } \\ & \end{array}$

